\title{
Editorial for the ACIS Selected Papers Section
}

\section{Associate Professor John Lamp}

AJ IS Editor-in-Chief

Deakin Business School

The Australasian Conference on Information Systems (ACIS) is the premiere information systems conference in the region. In 2014 it was hosted by the Department of Business Information Systems at the School of Business, Auckland University of Technology. They keynote speakers were Professor Robert M Davison, Department of Information Systems, City University of Hong Kong and Dr. J ürg von Känel, Associate Director of the "IBM Research Australia" Lab. The conference was extremely well attended as it was run back to back with the International Conference on Information Systems at the University of Auckland.

The Track Chairs were asked to nominate papers for inclusion in this special section of AJIS, and the authors of those papers were contacted and offered a place in this section. Some declined as they already had acceptances in other journals, or because of other commitments.

Authors were given the opportunity to update their papers for this Section and most have done so.

ACIS 2015 will be held at the University of South Australia, and we look forward to publishing selected papers from that conference in 2016.

Copyright: (C) 2015 Lamp. This is an open-access article distributed under the terms of the Creative Commons Attribution-NonCommercial 3.0 Australia License, which permits noncommercial use, distribution, and reproduction in any medium, provided the original author and AJ IS are credited.

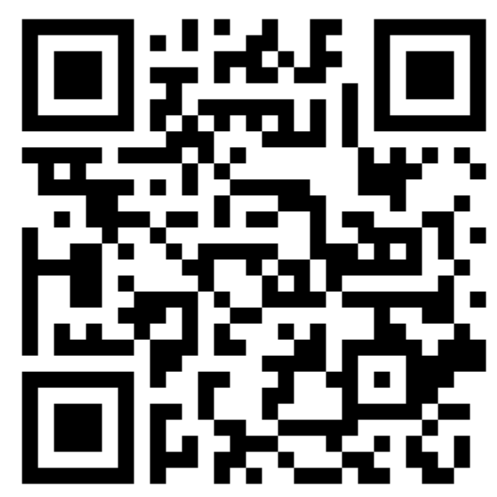

